\title{
Из наблюдений над способами выражения отрицания в церковнославянском тексте русского извода
}

\author{
Observations on the ways of expressing negation \\ in the Ruthenian recension of Church Slavonic text
}

\begin{abstract}
The article describes the specificity of the changes that took place in the process of dissemination of double negation, typical for Slavic languages, visible in the Ruthenian recension of Church Slavonic texts. The reflections on the achievements in the field are enriched with the results of research on the text of Gospel No. 7 from the collection of the Russian State Archive of Ancient Acts (RGADA F. 381. Op. 1 Unit hr 7), which has not been analyzed so far in terms of the issues raised. Nearly three hundred negative structures were subjected to observations. In order to determine the number of single negation cases in relation to double negation the main focus was on structures such as: (1) ni Pron + V, (2) ni Pron + ne V oraz (3) ne V + ni Pron. It was determined, among other things, that their use was influenced by both the literature tradition and live language with elements of the northern dialect of the East Slavonic. On the other hand, the analysis of the negative structures preceding homogeneous parts of the sentence revealed the tendency, manifested on the leaves of the monument, to transform towards the norm of the contemporary Russian language.
\end{abstract}

Keywords: Gospel Book, written records, Old Russian language, Church Slavonic language, negation

Zofia Szwed, Uniwersytet im. Adama Mickiewicza w Poznaniu, Poznań - Polska, z-szwed@amu. edu.pl, ORCID ID: https://orcid.org/0000-0002-4785-4797

Одной из особенностей, выделяющих славянские языки на фоне других индоевропейских языков, является двойное отрицание, заключающееся в употреблении отрицательной частицы не перед сказуемым при наличии ни в составе местоимения. Такого рода конструкции можно отметить в современных славянских языках, например: никой не чу (бол.), nitko nije с̌ио (хрв.), nikdo ne slyšel (чеш.), nikt nie styszat (пол.), ніхто не чув (укр.), никто не сльлиал (рус.). В некоторых других языках индоевропейского происхождения, особенно германских, в аналогичных случаях наблюдаем, как правило, одиночное отрицание. Иллюстрацией может послужить пример из англий- 
ского языка: no one heard . Вот как подытоживает выводы исследователей двойного отрицания в славянских языках Елена Кржижкова:

современное состояние славянских языков является результатом продолжительного развития, в течение которого исходное состояние с сосуществующей единой негацией типа латин. или современных германских языков и двойной негацией современных славянских языков развивалось в направлении к общему распространению двойной негации, в то время как в языках западноевропейских, в частности, в языках германских (положение во французском несколько сложнее), устанавливается единая негация (Kržižkova 21-22).

Церковнославянские тексты русского извода представляют собой интересный материал для исследований над распространением двойного отрицания в начальный - с XI по XIII вв. - период формирования русского письменного языка. Для текстов, написанных церковнославянским типом древнерусского языка, характерно последовательное сохранение кирилло-мефодиевской письменной традиции, согласно которой конструкция никто не сльшшал употреблялась в двух сосуществующих вариантах: в соответствующем индоевропейской традиции мононегативном варианте: никъто же сльшааше - и в варианте с отрицательной частицей не при сказуемом: никъто же не сльшааше, свойственном речи переводчиков (Haburgaev 403) и преобладающем в памятниках светской литературы (Borkovskij, Kuznecov 439).

В настоящей статье проводится анализ соотношения отрицательных конструкций указанного типа в тексте написанного около XIII в. Евангелия № 7 - полного апракоса из собрания Российского государственного архива древних актов (РГАДА Ф. 381. Оп. 1. Ед. хр. 7). Наблюдениям подвергаются также конструкции с отрицанием перед однородными членами предложения и перед однородными членами-сказуемыми. Целью исследований является установление, насколько рассматриваемые конструкции близки исходной норме, характерной для древнейших славянских памятников, а в какой степени они приближаются к норме современного русского языка.

Среди примерно трехсот выбранных из текста Евангелия № 7 и проанализированных отрицательных конструкций ключевыми для установления соотношения между одиночным и двойным отрицанием являются те, которые содержат в своем составе: 1) местоимение с ни и сказуемое (ni Pron + V); 2) местоимение с ни, отрицательную частицу не и сказуемое (ni Pron + ne V) и 3) отрицательную частицу не, сказуемое и местоимение с ни (ne $\mathrm{V}+\mathrm{ni}$

1 Речь идет о стандартном английском языке. В некоторых диалектах английского языка выступает двойная (а даже тройная) негация, однако в официальной ситуации и на письме она недопустима (Cambridge Dictionary. Web. 03.04.2020. https://dictionary.cambridge.org/ grammar/british-grammar/double-negatives-and-usage). 
Pron). В качестве иллюстрации ниже приводятся все отмеченные конструкции указанных типов:

\section{ni Pron + V:}

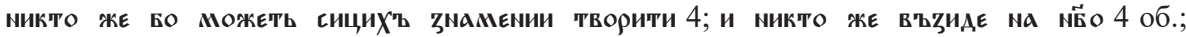

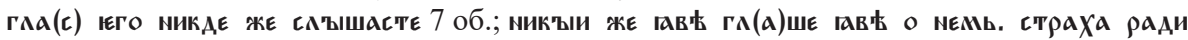

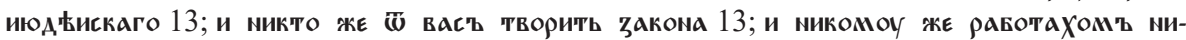

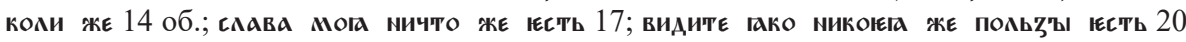

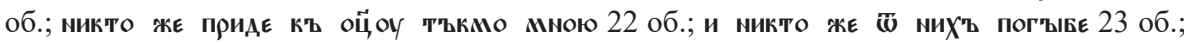

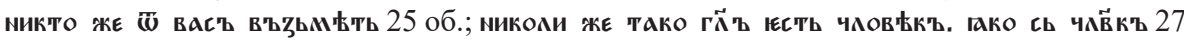

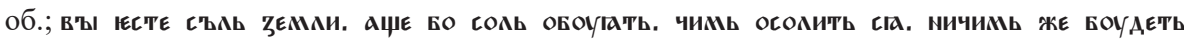

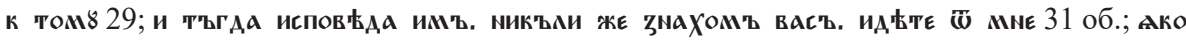

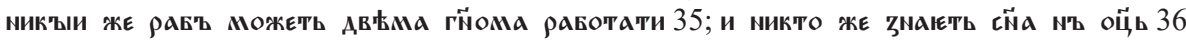

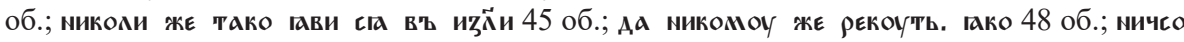

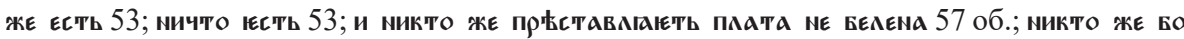

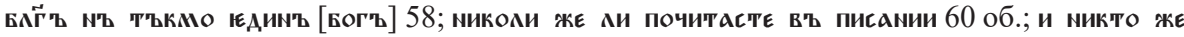

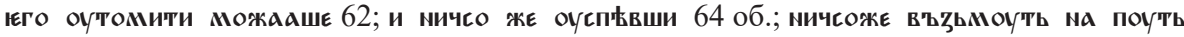

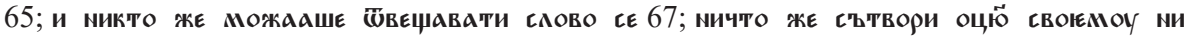

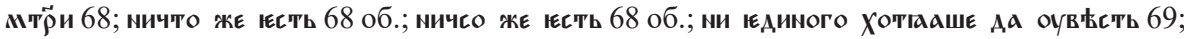

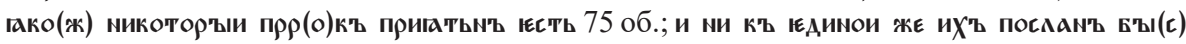

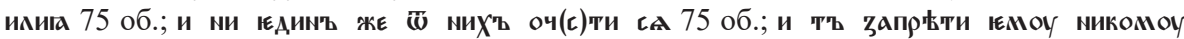

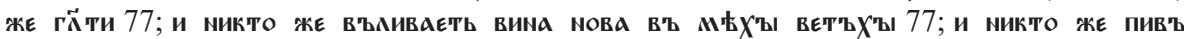

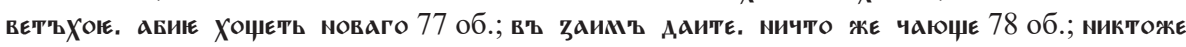

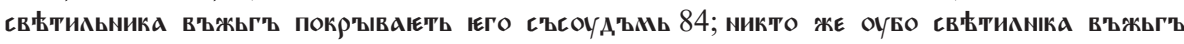

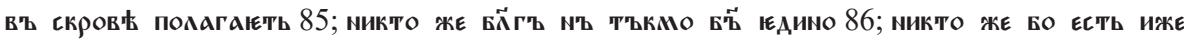

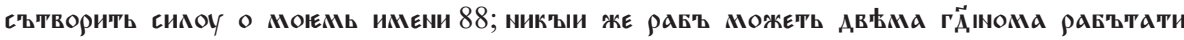

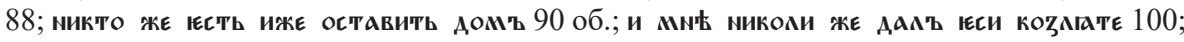

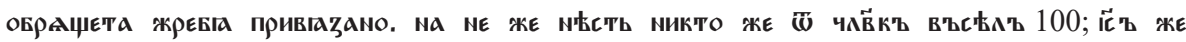

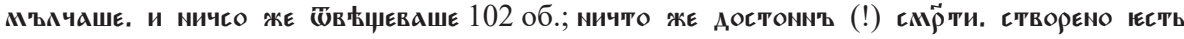

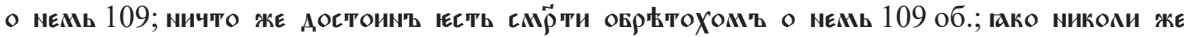

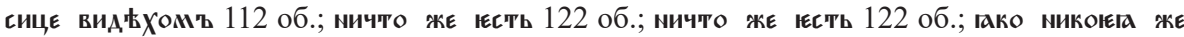

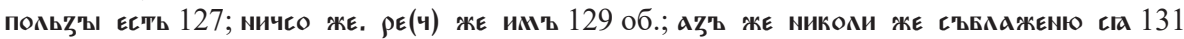

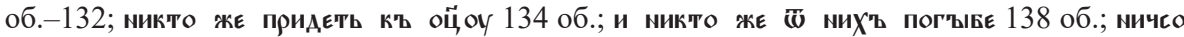

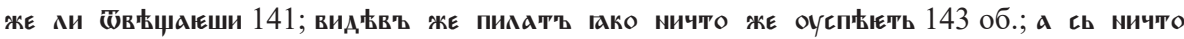

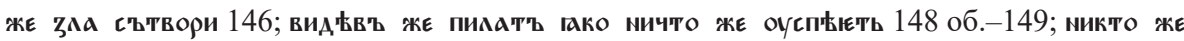

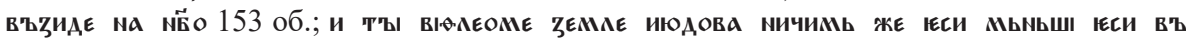

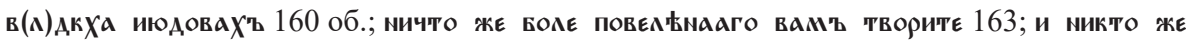

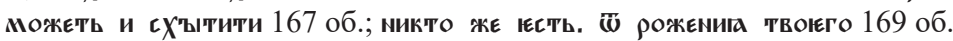

\section{ni Pron + ne V:}

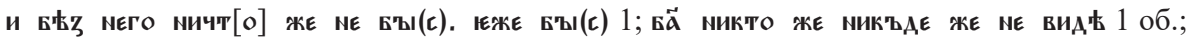

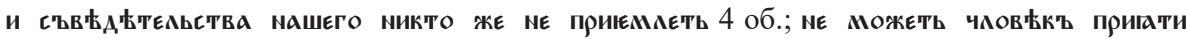

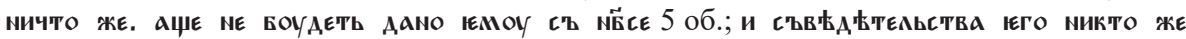

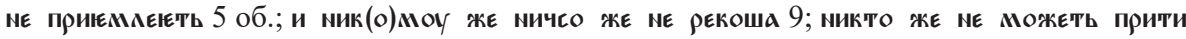

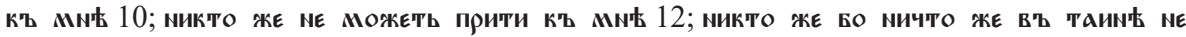

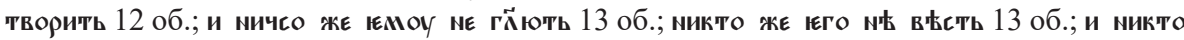

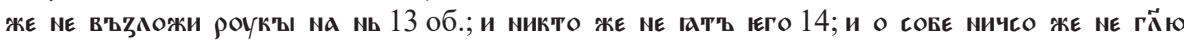

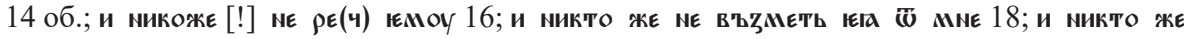




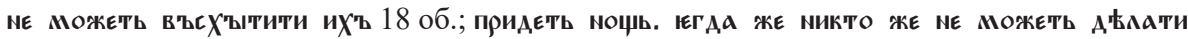

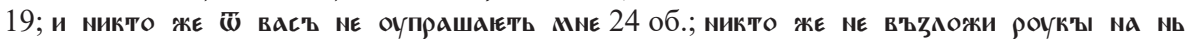

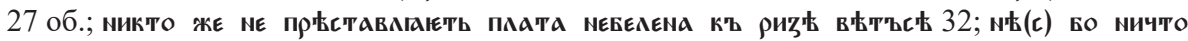

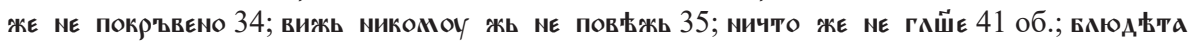

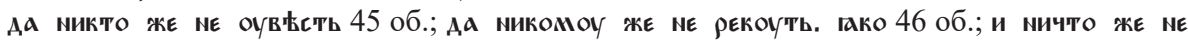

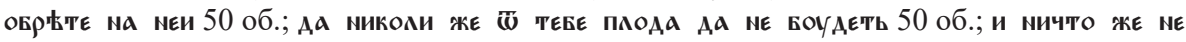

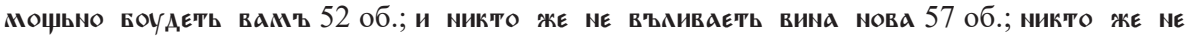

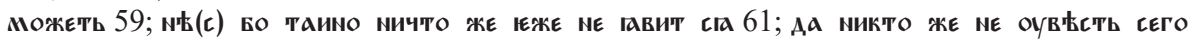

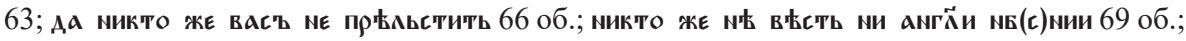

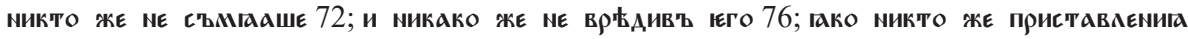

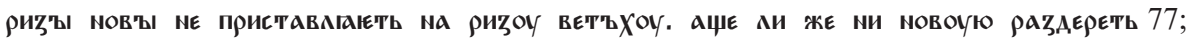

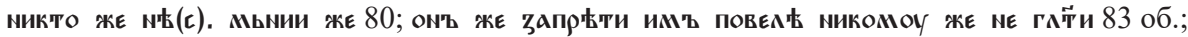

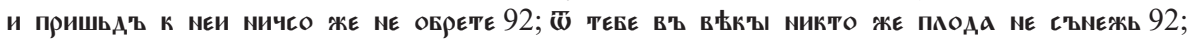

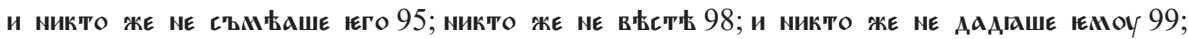

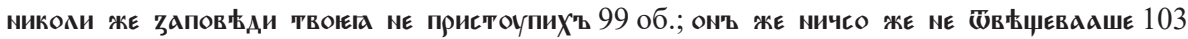

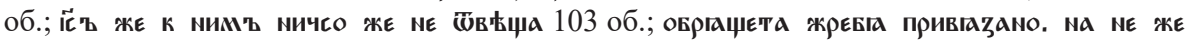

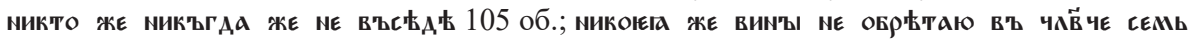

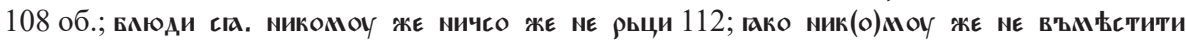

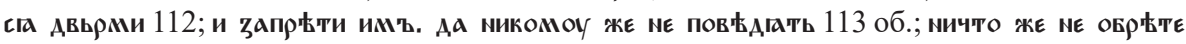

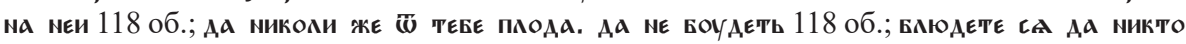

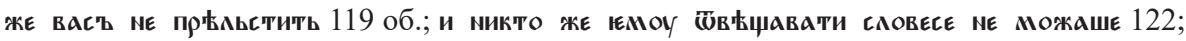

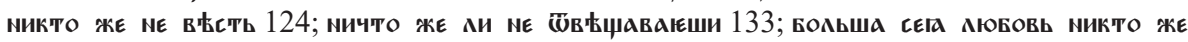

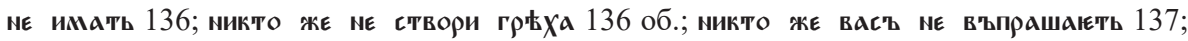

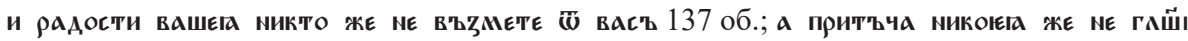

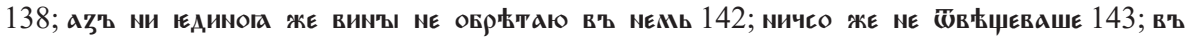

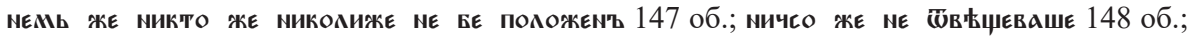

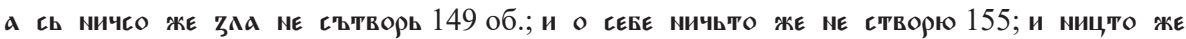

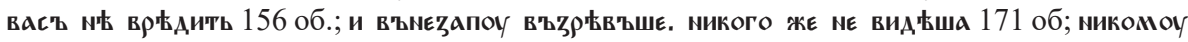

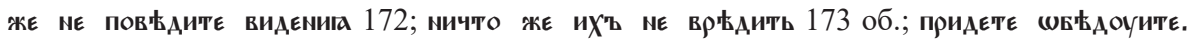

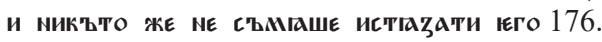

\section{ne $\mathrm{V}+$ ni Pron:}

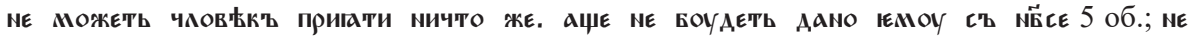

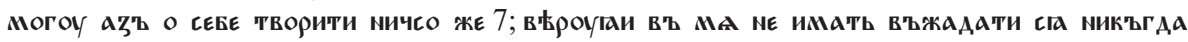

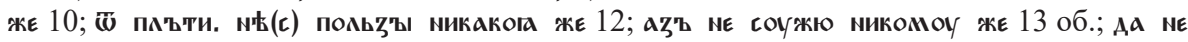

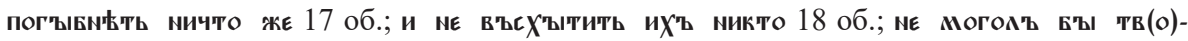

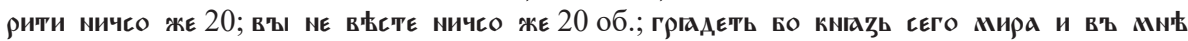

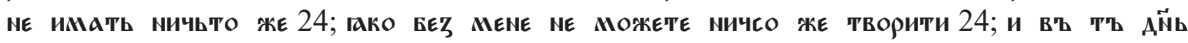

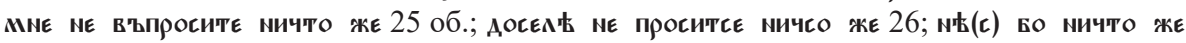

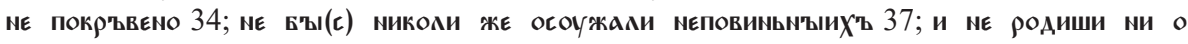

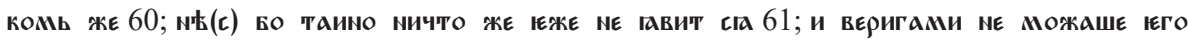

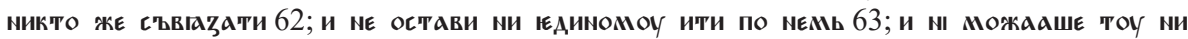

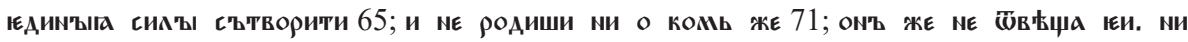

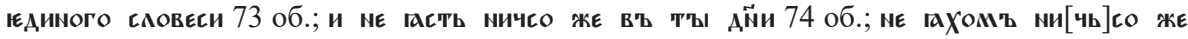

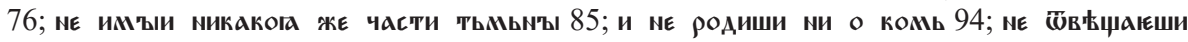

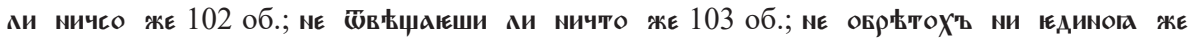

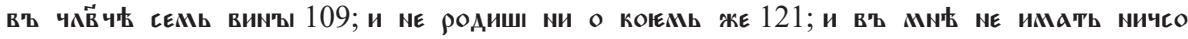

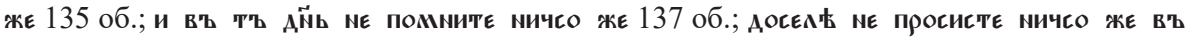

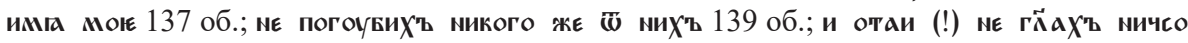




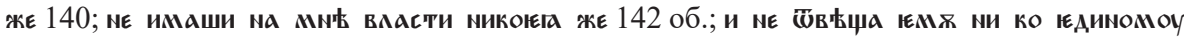

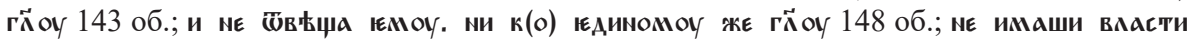

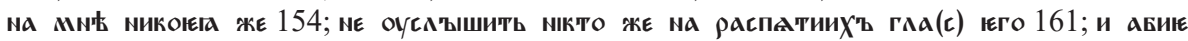

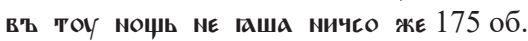

Отражающая одиночное отрицание конструкция ni Pron + V типа микто Же Бо можеть, отмечается 67 раз, в то время как Две остаЛьНЫе конструкции: ni Pron + ne V (nикто же ne приекметь) и ne V + ni Pron (ne coyжю nикомоy) представлены соответственно 76 и 41 примером. Таким образом, случаи двойного отрицания, засвидетельствованные вместе 117 раз, превышают случаи без добавочного отрицания при сказуемом (процентное соотношение одиночное-двойное отрицание составляет $36 \%$ и 64\% соответственно). Учитывая церковнославянский тип текста, количество отмеченных в нем предложений с двойным отрицанием, в свете слов Борковского, следовало бы считать большим:

из двух возможных для древнерусского языка оборотов (с не и без не) древнерусский книжник, под влиянием церковнославянской письменности, предпочитал употребить оборот без не, хотя последний, по-видимому, был менее широко распространен в диалектах русского языка (Borkovskij, Kuznecov 441).

Однако, в древнейших славянских рукописях - Ассеманиевом и Мариинском евангелиях - наблюдаем сходные статистики.

Таблица 1. Конструкции с отрицанием в древнейших славянских памятниках

\begin{tabular}{|l|c|c|c|}
\hline \multicolumn{1}{|c|}{ Рукопись } & Ассеманиево ев. $^{2}$ & Мариинское ев. & Евангелие № 7 \\
\hline ni Pron + V & $28 \%$ & $30 \%$ & $37 \%$ \\
\hline ni Pron + ne V & $\mathbf{4 7} \%$ & $\mathbf{5 3} \%$ & $\mathbf{4 1} \%$ \\
\hline ne V + ni Pron & $25 \%$ & $17 \%$ & $22 \%$ \\
\hline
\end{tabular}

Из таблицы видно, что в созданных в X-XI вв. древнецерковнославянских памятниках письменности, конструкции, содержащие двойное отрицание с отрицательным местоимением в препозиции, могут составлять довольно высокий процент.

В позднейших, созданных в XII - начале XIV вв. евангелиях русского извода, двойное отрицание может проявляться шире. Проверка нескольких избранных отрицательных конструкций в аналогичных чтениях трех древнерусских апракосов показывает, что на месте одиночного отрицания

${ }^{2}$ Статистические данные по Ассеманиеву и Мариинскому евангелиям приводятся по работе Е. Кржижковой (Kržižkova 24-25). 
в Евангелии № 7, в сопоставленных текстах наблюдаем двойное отрицание. Иллюстрацией могут послужить примеры, представленные в нижеприведенной таблице 3 .

Таблица 2. Выбранные конструкции с одиночным отрицанием в Евангелии № 7 в сопоставлении с данными Мстиславова, Евсевиева и Лаврашевского евангелий

\begin{tabular}{|c|c|}
\hline Евангелие № 7 & Мстиславово ев./Евсевиево ев./Лаврачевское ев. \\
\hline $\begin{array}{l}\text { МИКтО ЖЕ БО МОЖЕТЬ СИЦИХЪ ЗНАМЕКИИ ТВО९ИТИ } \\
4 \text { (ЧТ. СВ. НД., И. ІІІ 2) }\end{array}$ & 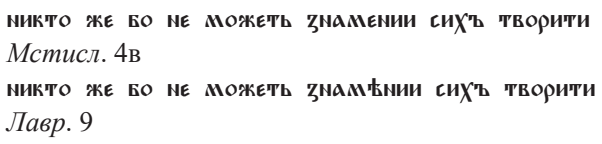 \\
\hline $\begin{array}{l}\text { никомоУ Же РаБотаХомъ Миколи Же } 14 \text { об. (сб. } 4 \\
\text { НД. По ПасХе, И. VIII. 33) }\end{array}$ & 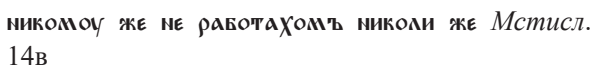 \\
\hline 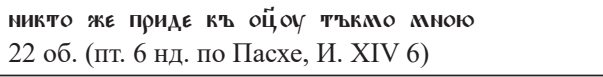 & $\begin{array}{l}\text { МИКТО ЖЕ МЕ ПРИИАЕТЬ КО ФЙЮ КО ТОЧЬЮ МНОЮ } \\
\text { Лавр. } 76\end{array}$ \\
\hline 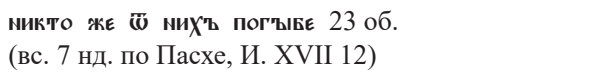 & 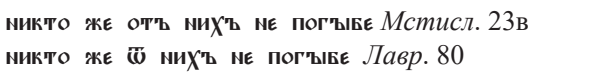 \\
\hline 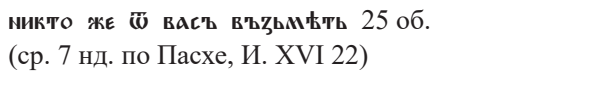 & 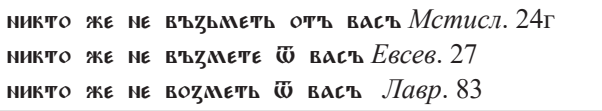 \\
\hline 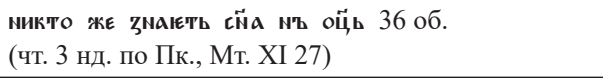 & 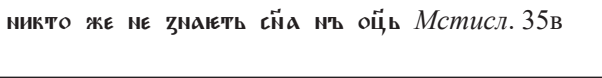 \\
\hline $\begin{array}{l}\text { Аа пикомоУ Же рекоуть. ГЯ̆ко } 48 \text { об. } \\
\text { (ср. } 8 \text { нД. По Пк., МФ. XVI 20) }\end{array}$ & 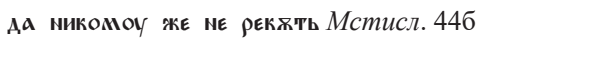 \\
\hline 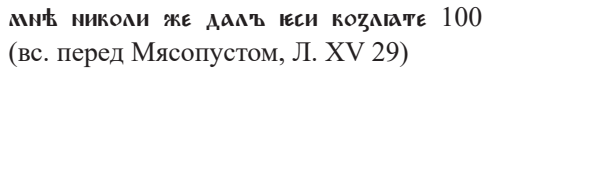 & 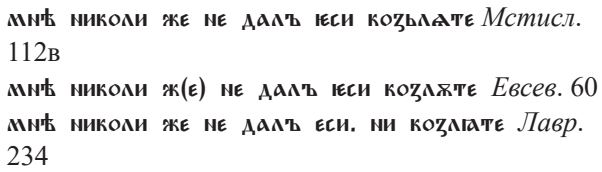 \\
\hline
\end{tabular}

Таким образом в Евангелии № 7 наблюдаем подобное распространение двойного отрицания как в приведенных древнецерковнославянских рукописях. В сопоставлении с евангелиями русского извода XII - начала XIV вв. в исследованном тексте в большей степени может сохраняться одиночное отрицание.

Среди факторов, которые могли оказать влияние на соотношение между одиночным и двойным отрицанием в Евангелии № 7, следует учитывать северное происхождение книги, на которое указывают, в частности, характерные для новгородского диалекта сочетания жг вместо жд на месте преж-

${ }^{3}$ В качестве источников сравнительного материала использованы: Мстиславово евангелие (до 1117 г.) (Мстисл.), Евсевиево евангелие 1283 г. (Евсев.) и Лаврашевское евангелие (XIII/XIV вв.) (Лавр.). 
них $*_{z d j}$, *zgj, *zg (Живов 51), например: ижгеметт 18, рожгиє 24, А'ъжгь 34об. bis, ижгеноут сга 38 - или многократное нарушение правил употребления аффрикат и и ч (Szwed 312-313). Как упоминается в работе Леонида Apceньевича Булаховского, „опущение не [перед глаголом при отрицании - Z.S.] в некоторых случаях [...] может быть фактом и русским, диалектным, имеющим параллели в сев.-русских говорах” (Bulahovskij 406, прим. 1). Широкое распространение оборотов без отрицания перед сказуемым, при наличии местоимения, начинающегося с ни, в современных северновеликорусских говорах отмечает Абрам Борисович Шапиро (Šapiro 198). Он считает отсутствие не при сказуемом одной из особенностей структуры отрицательных предложений в северном районе России, а в подтверждение приводит примеры, среди прочего, из говоров Вологодской и Архангельской областей (Šapiro 198). Однако данная черта распространена во многих говорах. Притом она не является всеобщей - наряду с ней, не реже, встречаются случаи употребления сказуемого с отрицанием (Šapiro 198).

Наличие мононегативных предложений в древнецерковнославянских переводах греческих религиозных книг первоначально привело исследователей к убеждению, что обороты без не при сказуемом заимствованы из греческого языка (Buslaev 327, Haburgaev 403), что они перешли в церковнославянские тексты „как подражание языку греческому” (Černyšev 17). Поэтому они воспринимались однозначно как особенность письменной традиции. Только позднейшие наблюдения над древнерусскими памятниками письменности, главным образом деловой, а также над отдельными русскими диалектами и говорами повлияли на изменение подхода к вопросу. Стало ясным, что оборот с одним отрицанием не был заимствованием из чужого языка (Borkovskij, Кузнецов 441). Мононегативность была особенностью индоевропейских языков, в том числе славянских, о чем свидетельствуют, наряду с данными древнерусских памятников и северновеликорусских говоров, черты мононегативности в современных сербском и хорватском языках (Baharev 18). Таким образом, мононегативность - это не заимствованное, а исконное для русского языка явление (Baharev 18).

В связи с вопросом перехода от одиночного отрицания к двойному, на раннем этапе развития русского литературного языка, отдельного рассмотрения требует, представленная в материале одним примером: они же рєкоша мичсо же 107, конструкция V + ni Pron, образующая пару для более распространенной модели ne $\mathbf{V}+$ ni Pron. Количественное соотношение между ними 1 к 41. По-видимому, конструкции, содержащие местоимение с ни в постпозиции, в первую очередь стали приобретать добавочное не при сказуемом, превращаясь в модель типа ne V + ni Pron. Одиночное отрицание с отрицательным местоимением в препозиции - ni Pron $+\mathbf{V}$, как показывает 
материал Евангелия № 7, продержалось дольше (выше мы отметили 67 примеров, образованных по этой модели). По наблюдениям Кржижковой:

\begin{abstract}
Простая негация с препозицией местоимения долгое время сохранялась, вероятно потому, что общеотрицательное местоимение в начале предложения достаточно выразительно сигнализировало общеотрицательное значение всего предложения в целом, в то время как отрицательное местоимение в постпозиции сигнализировало бы общеотрицательный характер предложения лишь в самом конце предложения (Kržižkova 31).
\end{abstract}

Со временем наступило проникновение глагольного отрицания также в конструкции с препозицией местоимения с ни (Kržižkova 31) - ni Pron + ne V. Эта модель получила наиболее широкое распространение как в приведенных южнославянских памятниках письменности, так и в Евангелии № 7.

Рассмотрим отмеченные в Евангелии № 7 конструкции с отрицанием перед однородными членами предложения и перед однородными членами-сказуемыми.

Между древнерусским и современным русским языком существует разница в употреблении частицы $н и$ перед однородными членами предложения. В древнерусском языке $н и$ перед первым однородным членом не выступает (Borkovskij, Kuznecov 442). Нормой современного языка является наличие ни также перед первым однородным членом. Естественно, в тексте, созданном около XIII в., таком как Евангелие № 7, в указанных синтаксических условиях можно ожидать вариативности. Взаимоотношение возможных вариантов может дать представление в определенном смысле о степени архаичности - новаторства рукописи. Так, в Евангелии № 7 отмечены следующие случаи с отсутствием ни перед первым однородным членом:

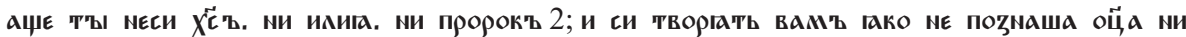

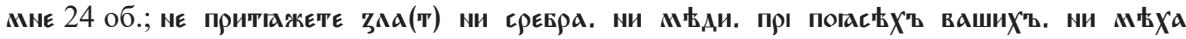

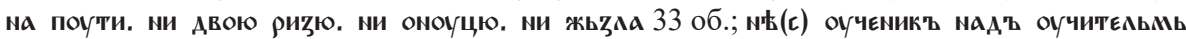

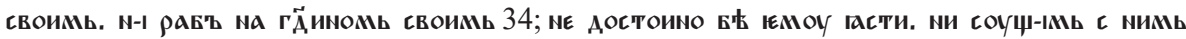

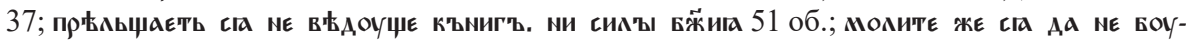

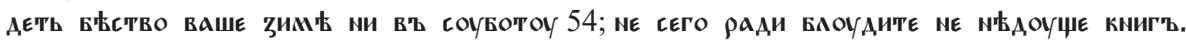

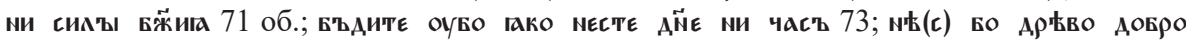

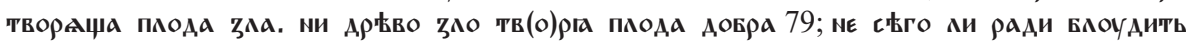

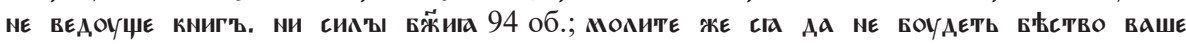

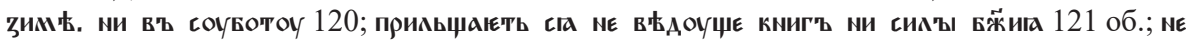

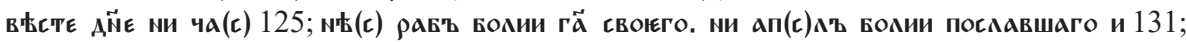

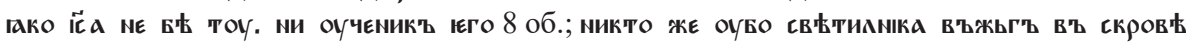

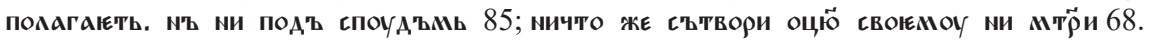

Свойственным древнерусскому языку предложениям без ни перед первым однородным членом противопоставляются следующие случаи соответствующие норме современного русского языка: 


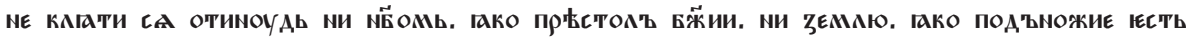

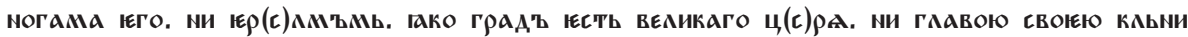
ᄃА 30; а ЕЖЕ

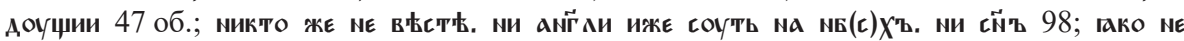

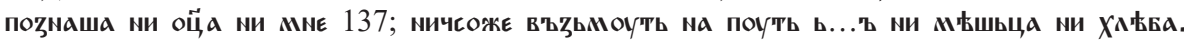

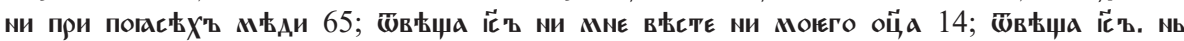

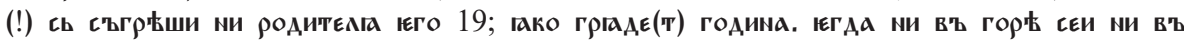
иеремй' Покмоните сга оц̆ю 15 об.

Как видно, в большинстве случаев отмечены примеры без ни при первом однородном члене, однако немало - почти одну треть - составили уже новые конструкции. Количественное соотношение обоих вариантов конструкций составляет $69 \%$ к $31 \%$.

Далее перейдем к результатам анализа случаев отрицания перед однородными членами-сказуемыми. Типичной для старославянских и древнерусских памятников письменности является постановка не перед первым сказуемым, а ни при последующих сказуемых (Borkovskij, Kuznecov 442). Согласно норме современного русского языка перед последующими сказуемыми ставится частица не. Распределение частиц ни и не при однородных сказуемых в тексте Евангелия № 7 представляется следующим образом. Подавляющее большинство материала можно свести к традиционной конструкции ne $\mathbf{V}+\mathbf{n i} \mathbf{V}$ :

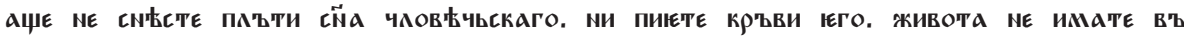

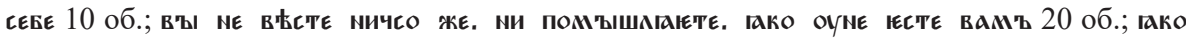

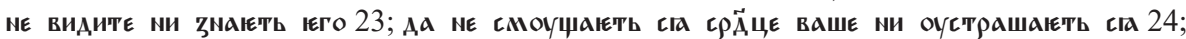

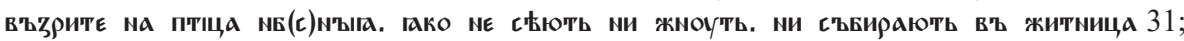

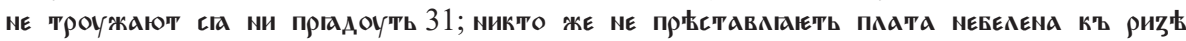

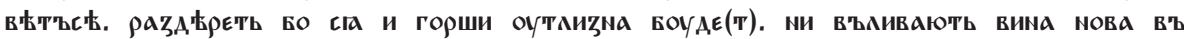

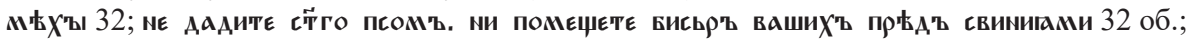

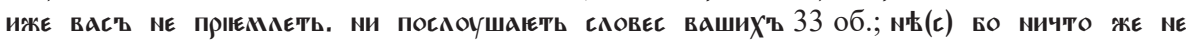

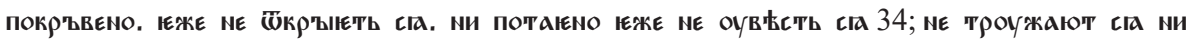

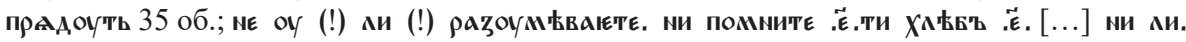

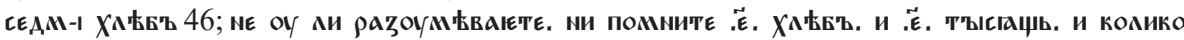

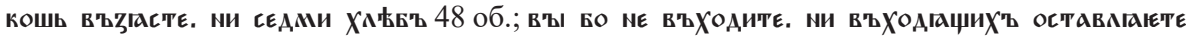

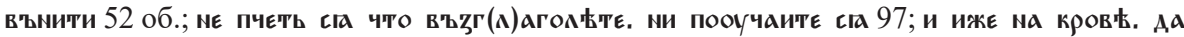

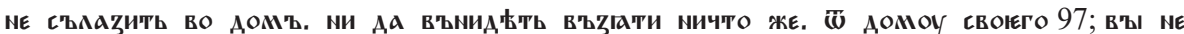

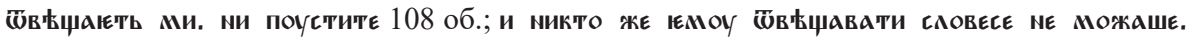

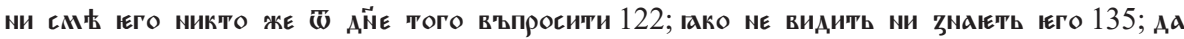

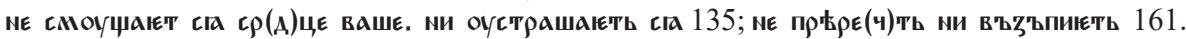

Современный вариант ne $\mathbf{V}+\mathbf{n e} \mathbf{V}$ в чистом виде не зафиксирован, однако встретилось предложение, образованное по модели ne $\mathbf{V}+\mathbf{n i} \mathbf{V}+$ ne V + ne V, в котором, правда, второму сказуемому предшествует частица ни, однако перед последующими - дважды фиксируется не: zаповњди вњси. ме оуьии. м⿰ 


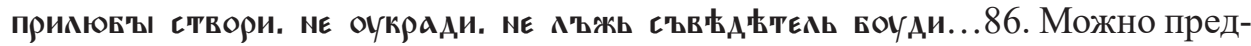
положить, что появление не перед третьим и четвертым сказуемым отражает изменения, которые стали происходить в направлении нормы, характерной для современного русского языка. Важно подчеркнуть, что во второй половине XIII в. не при очередных однородных сказуемых представляет собой инновацию даже в деловой письменности. Первый случай употребления не перед вторым сказуемым встречается в новгородской договорной грамоте,

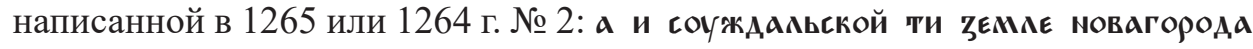
не ९Адити. ми волости(и)и ти не розАавати (Borkovskij, Kuznecov 443). Грамоту и Евангелие № 7 объединяет время - XIII в. и место происхождения - Север. Возможно, что наличие инновационного варианта с не в обоих памятниках неслучайно. Интересно было бы проверить аналогичные предложения в других, возникших на Севере текстах, созданных приблизительно в то же время.

\section{$* * *$}

Результаты анализа структуры отрицательных предложений в тексте Евангелия № 7 позволяют предполагать, что на соотношение между одиночным и двойным отрицанием имела влияние не только письменная традиция, но также живой язык с элементами севернорусского говора. Тенденцию к преобразованиям в сторону современной нормы русского языка в области выражения отрицания обнаруживают нередкие случаи наличия ни перед первым однородным членом, а также - пока единичное - предложение с повторяющимся, перед очередными однородными сказуемыми, не вместо традиционного ни.

\section{Источники}

Âgič, Ignatij V. Mariinskoe četveroevangelie. Pamâtnik glagoličeskoj pis'mennosti. BerlinSankt-Peterburg, Weidmann, 1883. Web. 29.08.2019. https://docviewer.yandex.com/?url =ya-disk-public \%3 A \%2F\%2FLacgVv2NduXXiDVNq0HurSpMD5TipZa 6\%2Fd YgToE3XGM\%3D\&name=Yagich\%20I.V.\%20Mariinskoe\%20chetveroevangelie.\%20 Pamyatnik\%20glagolicheskoj\%20pis'mennosti\%20(Berlin\%2C\%201883)(la)(K)(ToC) (300dpi)(637s).pdf\&page $=1 \& \mathrm{c}=53 \mathrm{e} 31 \mathrm{~d} 3 \mathrm{~d} 3438$.

Evangelie aprakos polnyj. RGADA f. 381, № 7. Web. 28.08.2019. http://rgada.info/kueh/index2. php?str=381_1_7\&name= $\%$ D0 $\% 95 \% \mathrm{D} 0 \% \mathrm{~B} 2 \% \mathrm{D} 0 \% \mathrm{~B} 0 \% \mathrm{D} 0 \% \mathrm{BD} \% \mathrm{D} 0 \% \mathrm{~B} 3 \% \mathrm{D} 0 \% \mathrm{~B} 5 \% \mathrm{D} 0$ $\%$ BB $\%$ D0\%B8\%D0\%B5\%20\%D0\%B0\%D0\%BF\%D1\%80\%D0\%B0\%D0\%BA\%D0\%BE $\% \mathrm{D} 1 \% 81 \% 20 \% \mathrm{D} 0 \% \mathrm{BF} \% \mathrm{D} 0 \% \mathrm{BE} \% \mathrm{D} 0 \% \mathrm{BB} \% \mathrm{D} 0 \% \mathrm{BD} \% \mathrm{D} 1 \% 8 \mathrm{~B} \% \mathrm{D} 0 \% \mathrm{~B}$.

Ewangeliarz Lawryszewski. Biblioteka Książąt Czartoryskich-Muzeum Narodowe w Krakowie, 2097 IV Rkps. Web. 29.08.2019. https://polona.pl/item/ewangeliarz-tzw-lawryszewskiaprakos-pelny,NzA4OTIwMTI/50/ \#info: metadata. 
Kurz, Josef. Evangeliár̆ Assemanuv. Díl II. Praha, Nakladatelství Československé Akademie Věd, 1955.

Nimčuk, Vasilij V. Evsevieve Evangelie 1283 roku. Kiiv, Kiïvs'kij Slavističnij universitet, 2001.

Žukovskaâ, Lidiâ P. Aprakos Mstislava Velikogo. Moskva, Nauka, 1983.

\section{Библиография}

Baharev, Aleksandr I. Otricanie v russkom âzyke. Suŝnost', sposoby vyraženiâ, istoriâ razvitiâ i sovremennoe sostoânie. Dissertaciâ doktora filologičeskih nauk. Taškent, 1996, Web. 26.08.2019. https://www.dissercat.com/content/otritsanie-v-russkom-yazyke-sushchnost-sposoby-vyrazheniya-istoriya-razvitiya-i-sovrem-sosto/read.

Borkovskij, Viktor I., Petr S. Kuznecov. Istoričeskâ̂ grammatika russkogo âzyka. Moskva, Nauka, 1965.

Bulahovskij, Leonid A. Istoričeskij kommentarij k russkomu literaturnomu âzyku. Kiev, Radâns'ka škola, 1958.

Buslaev, Fedor I. Istoričeskaâ grammatika russkogo âzyka. Moskva, Tipografiâ T. Ris, 1881. Web. 26.08.2019. http://books.e-heritage.ru/book/10075849.

Černyšev, Vasilij I. Otricanie ,,ne” v russkom âzyke. Material dlâ Slovarâ russkogo âzyka. Priloženie k I vypusku VIII toma Slovarâ russkogo âzyka. Leningrad, II Otdel Akademii nauk SSSR, 1927. Web. 31.03.2020. https://www.prlib.ru/item/355661.

Haburgaev, Georgij A. Staroslavânskij âzyk. Moskva, Prosveŝenie, 1974.

Kržižkova, Elena. „K voprosu o tak nazyvaemoj dvojnoj negacii v slavânskih âzykah”. Slavia, 37, 1, 1968, s. 21-39.

Šapiro, Abram B. Očerki po sintaksisu russkih narodnyh govorov: stroenie predloženiâ. Moskva, Izdatel'stvo Akademii nauk SSSR, 1953. Web. 31.03.2020. https://archive.org/ details/B-001-003-868/ page/n7.

Szwed, Zofia. „Pisownia afrykat «c» i «č» w Ewangeliarzu Tip-7 ze zbioru Rosyjskiego Państwowego Archiwum Akt Dawnych f. 381, nr 7”. Studia Rossica Posnaniensia, 43, 2018, s. 305-314.

Živov, Viktor M. Vostočnoslavânskoe pravopisanie XI-XIII veka. Moskva, Âzyki slavânskoj kul'tury, 2006. 